\title{
Editorial, Volume 5(1)
}

\author{
International \\ Journal for \\ Educational \\ Integrity
}

I am very pleased to welcome readers to Volume 5(2) of the International Journal for Educational Integrity.

Before introducing the current issue, I would like to begin with a couple of announcements. The $4^{\text {th }}$ Asia-Pacific Conference on Educational Integrity: Creating an Inclusive Approach will be held at the University of Wollongong, in New South Wales, Australia, from 28-30 September. The conference is built around a stimulating, discussion-centred format on a range of topics from plagiarism to values in teaching and learning, and the broader educational context. Presentation proposals and registrations are still being accepted. For full details, please go the conference website: http://www.uow.edu.au/conferences/4APCEI 2009/home.html

Shortly after $4 \mathrm{APCEI}$, the Center for Academic Integrity will hold its Annual Conference. Creating a culture of integrity: Research and best practices will be held at Washington University in St Louis, Missouri, USA, from 16-18 October. Proposals relating to current trends in academic integrity, data on the success rates of various approaches to academic integrity initiatives, innovative new approaches and models of best practices are invited. For full details, please go the conference website: http:// www.academicintegrity.org/conferences/2009 Conference/index.php

This edition of the IJEI includes two full papers and four reviews of recently published books on issues relating to educational integrity. Brian Martin opens the journal with an expansive essay which elaborates on the little explored topic of 'academic patronage'. Martin defines academic patronage as the bias and discrimination that occurs through decisions made, processes used, assistance given to individuals and personal interactions in academia. After providing careful descriptions of the various forms of academic patronage, Martin uses the example of honours thesis examining to illustrate some of the tensions inherent in a practice with "considerable potential for patronage". While acknowledging the value of mentoring, such as supporting research students, and providing training, advice, references and job opportunities, Martin makes the case that academic patronage has the potential to undermine the meritocratic foundation of academia.

In the second paper of this issue, Malcolm Rees and Lisa Emerson share a revised version of their presentation from the $3^{\text {rd }}$ International Plagiarism Conference at Northumbria University in June 2008. Based on structured interviews with nine staff members at Massey University in New Zealand, Rees and Emerson extend the research on electronic detection of plagiarism by exploring the impact that the textmatching software program, Turnitin, has had on assessment practice. They asked staff if their use of Turnitin in traditional text-based assessments had resulted in alternative assessment approaches to reduce incidences of plagiarism, and to encourage students to work effectively with secondary source material. Although the authors found that seven of the nine staff members surveyed had not changed their assessment practices, two cases of innovative practice were identified and are showcased in the paper.

The last 12 months has seen the publication of some truly outstanding books on academic integrity, and the second part of the current issue provides reviews of four

The International Journal for Educational Integrity is available online at:

http://www.ojs.unisa.edu.au/journals/index.php//JEI/

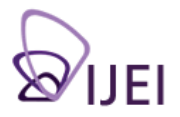


of these texts. I was fortunate to be given a sneak preview of Cheating in School: What we know and what we can do (Stephen F. Davis, Patrick F. Drinan and Tricia Bertram Gallant) due to be released in August this year by Wiley-Blackwell. Julianne East from La Trobe University in Melbourne reviews Rebecca Moore Howard's and Amy Robillard's Pluralizing plagiarism: Identities, Contexts, Pedagogies, published by Boynton/Cook last year; Ursula McGowan from the University of Adelaide, South Australia, reviews Pedagogy, not policing: Positive approaches to academic integrity at the university (Tyra Twomey, Holly White and Ken Sagendorf), published earlier this year by the Graduate School Press at Syracuse University; and Ruth Walker from the University of Wollongong, New South Wales, reviews Caroline Eisner's and Martha Vicinus' edited collection Originality, Imitation and Plagiarism: Teaching Writing in the Digital Age (2008). These books, all published in the U.S., provide diverse perspectives on the multi-faceted topic of academic integrity. What brings them together is the clear commitment from each of the authors to move away from a simplistic and/or punitive focus on student plagiarism to examine the broader educational context.

Academic integrity is the commitment to five fundamental values: honesty, trust, fairness, respect and responsibility (Center for Academic Integrity 2009). This view of integrity as a "clustering of values beyond honesty" (Davis, Drinan \& Bertram Gallant, 2009, forthcoming, p. 26), involves much more than a commitment from students not to cheat. The Center for Academic Integrity (CAI) makes explicit that academic integrity is multi-dimensional and is enabled by all those in the educational enterprise, from students to parents, instructors and administrators. It is for this reason that the CAl's counterpart and sponsor of this journal, the Asia Pacific Forum on Educational Integrity (APFEI), prefaces 'integrity' with 'educational' rather than 'academic'. From the first conference in 2003, we have attempted to encapsulate the complex aspects and numerous stakeholders of integrity across the various educational sectors, with a clear intention not to limit the topic to universities (Bretag \& Green, 2009, under review). It is evident from the books reviewed in this issue that the field of academic/ educational integrity is attracting researchers with a sophisticated understanding of the issues that go well beyond student plagiarism, writing practices or even research ethics.

Tracey Bretag, Editor IJEI

\section{References}

Bretag, T. \& Green, M. (2009, under review). Determining outcomes for academic misconduct: Is it more important to be consistent or fair? Paper submitted for review to the $4^{\text {th }}$ Asia-Pacific Conference on Educational Integrity: Creating an Inclusive Approach, University of Wollongong, 28-30 September 2009.

Center for Academic Integrity (2009). Retrieved May 28, 2009 from http:// www.academicintegrity.org/index.php

Davis, S. F., Drinan, P. F. \& Bertram Gallant, T. (2009, forthcoming). Cheating in school: What we know and what we can do. MA, USA: Wiley Blackwell, Malden. 